\title{
Perspectives
}

\section{PBLA: Moving Toward Sustainability}

Tara Holmes

The introduction of Portfolio-Based Language Assessment (PBLA) into federally funded Language Instruction for Newcomers to Canada (LINC) programs is a major national initiative. This comprehensive approach to classroom-based assessment, aligned to the Canadian Language Benchmarks standards, incorporates current perspectives on assessment and draws heavily on Assessment for Learning (AfL) research and principles. This article describes the PBLA initiative in relation to the research that informs it and outlines the approach that is being used to introduce PBLA into adult ESL programs. The article introduces a model of sustainability proposed by researchers who have led AfL initiatives internationally. Key learning from these initiatives points to implications for PBLA; the author suggests directions for PBLA moving forward.

L'intégration de l'évaluation linguistique basée sur le portefeuille (PortfolioBased Language Assessment - PBLA) dans les programmes subventionnés par le gouvernement fédéral des Cours de langue pour les immigrants au Canada (CLIC) représente une l'initiative nationale majeure. Cette approche globale à l'évaluation en classe, conforme aux niveaux de compétence linguistique canadien, intègre les perspectives actuelles sur l'évaluation et s'appuie fortement sur la recherche et les principes de l'évaluation au service de l'apprentissage (AfL). Cet article décrit l'intiative de la PBLA par rapport à la recherche qui l'éclaire, et dresse les grandes lignes de l'approche employée pour l'intégrer aux programmes d'ALS pour adultes. De plus, on y présente un modèle de durabilité proposé par les chercheurs qui ont mené des initiatives d'AfL sur le plan international. Les principales leçons de ces initiatives comprennent des incidences pour la PBLA et l'auteure proposent des pistes pour la faire progresser.

The introduction of Portfolio-Based Language Assessment (PBLA) in Canada has been a major national initiative that is unique in breadth and scope. PBLA was initially undertaken by Citizenship and Immigration Canada (CIC) in response to several studies on language training in Canada (Makosky, 2008; Nagy \& Stewart, 2009) that recommended a teacher-based assessment protocol be introduced in federally funded English as a second language training programs for adults, known in Canada as Language Instruction for Newcomers to Canada (LINC) programs. In 2009, an intergovernmental study of settlement language training across Canada advised CIC to adopt a language 
portfolio assessment system (Pettis, 2014, p. 3). As a result, PBLA is now being introduced into LINC classrooms across Canada, managed through the Centre for Canadian Language Benchmarks (CCLB). In Canada, the CCLB is the centre of expertise in support of the national standards for measuring and recognizing English and French second language proficiency of adult immigrants and prospective immigrants. Recently, the province of Ontario has joined the initiative, supporting the introduction of PBLA into their adult ESL programs through funding from the provincial Ministry of Citizenship, Immigration and International Trade. At the time of writing, the project is at a midpoint in the initial introduction of PBLA into ESL classrooms. By April 2017 an estimated 2,500 instructors will be using PBLA in their adult ESL classrooms, supported by approximately 420 lead instructors.

While the Canadian PBLA initiative is unique, requiring us to "make the road by walking," we benefit from the experiences of other international initiatives as we now move from the introduction of PBLA in classrooms to the sustainability of the initiative over the coming years.

\section{Looking Back: The Foundations}

CIC set out to establish an assessment approach that would support learning, introduce a common standard of practice, and improve CIC's ability to determine the impact of language training in LINC programs. In 2009, they seconded Joanne Pettis from Labour and Immigration in the province of Manitoba to develop a national portfolio language assessment approach modelled on an existing provincial initiative. This first step eventually led to the development of our project team, which included two project leads and several regional coaches, all working through the CCLB.

In the early stages of development, the national PBLA initiative was linked to the already established principles and standards of the Canadian Language Benchmarks. The term "portfolio-based language assessment" is widely used to describe an approach to assessment; in this article, the term PBLA is used to describe the specific approach being introduced through this CIC-supported national initiative. This approach integrated many of the principles of Assessment for Learning (AfL), as developed over the past two decades by UK assessment reformers, who initially came together in 1989 in the UK to ensure that assessment policy and practice were based on relevant research evidence. The group became known as the Assessment Reform Group; their work has led to a broad understanding of assessment, including several strategies that became foundational to PBLA (Pettis, 2014).

In a seminal study (Black \& Wiliam, 1998), members of the group reviewed over 250 quantitative research studies, and concluded that innovative formative assessment practices can raise standards and promote effective lifelong learning. The study was foundational to the current understanding that formative assessment and summative assessment are interrelated, and 
that all assessment should be formative in nature. The discussions that followed Black and Wiliam's (1998) work produced several AfL principles and strategies, many of which are foundational to PBLA.

\section{Incorporating Key Assessment for Learning (AfL) Strategies}

The Assessment Reform Group made a case for a strong link between assessment and instruction, arguing that assessment has great potential for improving both teaching and learning when embedded directly in instructional practice. Eventually, five key AfL strategies were identified, based on extensive research and work with classroom instructors (Leahy, Lyon, Thompson, \& Wiliam 2005; Wiliam, 2011). These strategies were key to the development and implementation of PBLA (Pettis, 2014, pp. 15-18):

- Strategy 1: Clarify learning intents and criteria for success. In PBLA, instructors articulate learning goals for all tasks, along with criteria for success, which are shared with learners and later used for learner feedback.

- Strategy 2: Incorporate classroom activities that elicit evidence of learning. In PBLA, instructors actively gather information on learning, as a basis for conversation with individual learners and for use in adjusting instruction.

- Strategy 3: Provide action-oriented feedback that moves learners forward. In PBLA, feedback addresses what the learner needs to do to improve and provides opportunities for learners to act on the information.

- Strategy 4: Activate learners to become instructional resources for one another. In PBLA, instructors look for ways to engage learners in supporting one another, including peer-assessment of learning.

- Strategy 5: Activate learners to become owners of their learning. In PBLA, learners use agreed-on criteria for self-assessment and engage in learning reflection.

These and other understandings of AfL introduced by members of the Assessment Reform Group led to a profusion of international initiatives. From 2006 to 2008, the group further advanced the discussion of AfL, through their involvement in the Analysis and Review of Innovations in Assessment (ARIA) project, which brought together more than 200 experts to discuss key issues relating to AfL initiatives. Their discussions revealed a number of principles for the ongoing development of AfL, including the need for widely agreed-upon standards, understood as practices to aspire to (Harlen \& Gardner, 2010), discussed in this article in the context of PBLA sustainability.

\section{Fostering the Dependability of Classroom-Based Assessment}

The increased emphasis on AfL strategies led to further research of the advantages of classroom-based assessment, and the professional role of instructors in that assessment (Black, Harrison, Lee, Marshall, \& Wiliam, 2003; Davison \& Leung, 2009; Gardner, Harlen, Hayward, Stobart, \& Montgomery, 2010; Harlen, 2004, 2005; Klenowski \& Wyatt-Smith, 2014; Leahy \& Wiliam, 2011). 
Part of this discussion has focused on the dependability of classroombased assessment. In a review of 30 studies, Harlen (2004) found that assessments by instructors can provide accurate summative information when specific conditions are met. Additionally, in the King's Oxfordshire Summative Assessment Project (KOSAP), a longitudinal study, teacher educators/ researchers explored strategies for enhancing the quality of summative assessments and facilitating a positive interaction between formative and summative assessment practices (Black, Harrison, Hodgen, Marshall, \& Serret, 2011). Together, the two studies outline a number of conditions for quality classroom-based assessment.

Both studies found that designing tasks gives teachers a deep understanding of learning goals and criteria, and that this understanding is in turn key to task and assessment validity. For this reason, Harlen (2005) argues that programs should support teachers in the development of classroom-based tasks and criteria, rather than defaulting to standardized assessment tasks (p. 267). The KOSAP study found that the careful implementation of tasks was key to effective assessment, including how tasks and criteria were introduced in the class, the amount of scaffolding provided, and the use of peer assessment. Instructors in the KOSAP study specifically explored how assessment for summative purposes could be embedded in classroom work and how learner portfolios could be structured to include a range of tasks appropriate to the learning goals.

Both the Harlen and KOSAP studies also found that the dependability of summative results lies in a shared interpretation of assessment criteria. Both emphasized the value of moderation sessions in which instructors look at learner work together, as an important step in developing a shared understanding of standards and related assessment criteria.

To foster both task and assessment dependability, PBLA integrates many of these measures. Instructors develop tasks and criteria that align with CLB standards and learner-identified interests and goals, share criteria with learners, encourage learner self-assessment and learning reflection, and collect a balance and range of tasks in portfolios. Instructors are also encouraged to collaborate in the interpretation of assessment criteria and development of tasks. In an early review of the implementation of PBLA to date (Ripley, 2012), instructors identified collaboration with colleagues to provide consistent assessment across classrooms as one of the key observed benefits of PBLA.

\section{PBLA Today: Implementation}

The introduction of PBLA into all LINC programs nationwide, and into provincially funded ESL programs in Ontario, has been and continues to be an ambitious endeavour. The roll-out plan incorporated learning from two pilot projects, the first in 2010-2011 with Ottawa LINC programs, and the second in 2011-2012 with LINC programs in Edmonton and New Brunswick. The 
national rollout of PBLA following these pilot projects has used a train-thetrainer or "cascade" approach.

Harlen (2010) suggests that pilot and roll-out or cascade approaches may have initial success in the development phase of large-scale innovations, but, after introduction, they need careful support to maximize genuine participation and ensure long-term integration of key understandings, transformation of practice rather than mere transmission of good practices (Gardner, 2010). To facilitate this sort of long-term and in-depth integration of classroom assessment practices, the PBLA implementation team is led by 2 project leads and supported by 12 regional coaches, selected for their experience as mentors and expertise in using the CLB and portfolios for classroom planning and assessment. These coaches support the development of assessment practices at the regional and local levels.

\section{Supporting Change of Practice: Lead Instructors}

In the early stages of local implementation, PBLA is introduced to program administrators through a one-hour webinar, after which administrators nominate lead instructors from within their programs, based on their classroom teaching skills, expertise in using the CLB, and informal leadership qualities. The lead instructors introduce PBLA to colleagues and support them through implementation.

In the UK, ARIA project researchers concluded that attempts to change practice in education must aim for a change in understanding rather than a superficial change in teaching techniques (Gardner, 2010). To foster committed learning, the 12-week online PBLA Foundations course introduces lead instructors to core PBLA principles and practices through a variety of readings, videos, application activities, and discussions.

After completing the course, lead instructors begin the Application Phase in which they (a) introduce PBLA in their own classrooms for a period of 12 to 14 weeks, (b) complete further work-in-progress submissions and reflections, and (c) submit a learner portfolio and get feedback from their regional coach. They are further supported through an online forum, where they can ask questions and engage in discussions with their regional coach and other lead instructors. Upon successful completion of the PBLA Foundations course and the Application Phase, they are certified as lead instructors.

\section{Supporting Change of Practice: Instructors and Programs}

Large-scale dissemination programs such as PBLA tend out of necessity to be "top-down" rather than "bottom up," resulting in fewer opportunities to tailor experiences to individual needs. However, Harlen (2010) suggests that even in large-scale initiatives, reflective and practice-relevant content and structure can support collaborative learning that enables instructors to put new ideas into practice in their own schools and classrooms. In the implementation of PBLA in individual programs and classrooms, therefore, 
our goal has been participation by all stakeholders in the exploration of AfL principles, applied in practice in different classroom contexts.

To introduce PBLA locally, lead instructors and local program administrators plan the implementation process with their regional coach. Lead instructors then introduce PBLA to colleagues over a period of five to seven months, via a series of workshops, each of which introduces a key PBLA principle or practice and includes opportunities for instructors to discuss the implications for their own teaching context. Between sessions, instructors try out strategies in their own classrooms and share learning and reflections. During this period, lead instructors are again supported through an online forum.

Once the workshops have been completed, classroom instructors introduce PBLA in their classrooms. For the first year of implementation, further opportunities to deepen learning are provided through end-of-semester portfolio review sessions that focus on assessment issues, portfolio evaluations, learner conferences, and progress reports.

\section{Looking Forward: Sustainability}

Long-term sustainability has been a goal of the PBLA project from the outset. Based on understandings arising from the ARIA project, Gardner et al. (2010) present a model of sustainability (Figure 1) that seems well-suited to inform the PBLA initiative as it moves forward. They suggest that several elements in the change process interact in a "complex, interwoven, and interdependent manner" (Gardner, 2010, p. 8).

If the model is used to interpret the PBLA initiative, the full range of PBLA practices and protocols would constitute the first element-innovation. The strong evidence that supports teacher-based assessment as a viable and powerful classroom process - evidence that starts with the 1998 Black and Wiliam study and includes the many others that have followed-would constitute the warrant. Our approach in rolling out the PBLA initiative fits as the dissemination element. As such, PBLA might be described as an innovation in the midst of dissemination or nearing the end of the dissemination process.

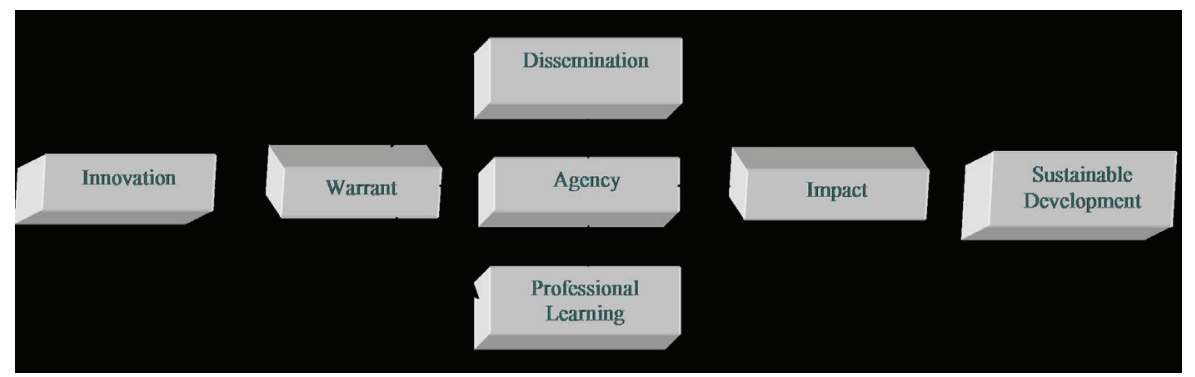

Figure 1: Key processes in ensuring sustainable change (Gardner, 2010, p. 8). Reprinted with permission from McGraw-Hill. 
The remaining elements of the model (agency, professional learning, impact, and sustainable development) provide guidelines for supporting the PBLA initiative in Canada in the upcoming years.

\section{Professional Learning and Agency}

Unless instructors are committed through self-agency to a particular change, the likelihood of successful integration of an innovation is low (Holmes, Gardner, \& Galanouli, 2007). Holmes et al. (2007) suggest that, if this commitment is to develop, instructors must be aware of the change being proposed and the evidence for its impact on learner motivation and achievement. Instructors must also perceive that the change will support their teaching. Only then will instructors be open to learning and implementing new ideas, and to reflecting on how these ideas might change their own practice.

The national PBLA implementation process has begun to facilitate this sort of instructor engagement in and commitment to professional learning and change. For PBLA practice to be sustained through evolving classroom and system realities, however, three key professional learning components will need to be maintained:

- Professional learning experiences that encourage instructors to continue to deepen their understanding of assessment principles and to try out new strategies in their classrooms;

- Local and online spaces where instructors can (a) reflect on practice, including their experimentation with new ideas and strategies, and (b) collaborate with other instructors who share their engagement in classroom-based assessment;

- Systemic support of professional learning, by including administrators in professional learning about assessment innovation, and by seeking continued funding and other evidence of official support for change.

\section{Impact}

For an innovative program to continue, it must demonstrate effectiveness to those involved in the change, and to those looking on: funders, policy makers, and researchers in the field. The program must both have an impact and be seen to have an impact.

In the ARIA study, many of the projects reviewed had multiple goals, with broad aims and very general outcomes, and in most cases the evidence of change or improvement was reported by instructors. Stobart (2010) argues that, although instructor advocacy for the effectiveness of a classroom innovation is powerful, it may not provide sufficient evidence for external policy makers and researchers. He suggests projects should provide systematic information about the impact of change, taking into account not only baseline indicators, intended outcomes, and evidence of actual outcomes, but also unintended outcomes and interpretations, including alternate explanations (Stobart, 2010, p. 145). 
Stobart (2010) also provides guidelines for how a project like PBLA might gather evidence of successful change: by clearly identifying the intended outcomes and criteria for success, triangulating multiple lines of evidence that point in the same direction, and incorporating strategies, such as surveys, to minimize the burden that impact studies put on participants.

\section{Sustainable Development}

The context in which an innovation is introduced is never static. Good assessment practice requires ongoing response to dynamic and ever-changing contexts: instructors must have the opportunity to review their assessment practices as their needs and the needs of learners change over time.

Harlen and Hayward (2010) draw on the work of Cullingford (2004), who suggests that sustainability has two dimensions: scientific and moral. The scientific aspect would be sustaining assessment practices that are based on research evidence and contextualized in classroom experience. The moral aspect recognizes that all of us who are involved in assessment are affected by each other's actions, and that sustaining an initiative requires negotiating across competing interests and values, while keeping the provision of the best possible learning experiences for learners central.

Sustainability of PBLA will be a complex process, but one that will benefit from maintaining the core values of AfL and from keeping specific research learnings in mind, in the contexts of both national and regional applications. Harlen and Hayward (2010, p. 157) suggest several values that can help maintain flexibility and relevance in our national assessment process in the upcoming years, values attached to three broadly defined groups: reflective practitioners who direct their own learning and collaborate to develop learner-responsive activities; active learners who are engaged in their own learning; and administrators, advisors, and policy makers who are committed to effective pedagogical practices and an assessment system flexible enough to allow all practitioners to adapt it to their own contexts without losing key features (Harlen \& Hayward, 2010, p. 157).

AfL studies have also provided a number of specific understandings that have implications for PBLA (Harlen \& Hayward, 2010, pp. 168-169). These understandings are summarized below, with implications for the sustainability of PBLA.

1. Instructors, lead instructors, and others need regular opportunities to discuss their assessment practices and to learn from each other; professional development must be continuous, recognizing that effective work requires ongoing commitment.

a. Going forward, ongoing opportunities for professional learning that provide time for instructors to talk through ideas and reflect on their assessment practices should be maintained.

b. Additionally, ongoing, bottom-up collaborative initiatives such as the development of resources by and for classroom instructors should be 
initiated, to maximize the "energizing effect of participative models of development" (Harlen \& Hayward, 2010, p. 170).

2. Instructors must see what they are doing as worthwhile and consistent with their own and national goals for learning. Instructors and others must have evidence of positive impact on learning. To sustain change, a range of research initiatives should be supported:

a. Instructor action-research studies to enhance engagement and deepen professional learning;

b. Impact studies that focus on the dependability of instructor-based assessment;

c. Research studies that focus on the impact of PBLA on language learners in Canada, a need that was also recognized by Ripley (2012).

3. The information provided through assessment needs to be useful to and valued by those receiving it; learners need to be aware of their role in assessment. Studies that gather feedback from learners about the impact of PBLA on their engagement in learning should be supported.

4. There should be consistency between different parts within the whole assessment system.

a. Going forward, broad standards, statements of quality practices to aspire to, should be developed and agreed upon by all stakeholdersclassroom instructors, administrators, policy makers, and researchers. This will enhance shared understanding of the principles of PBLA to support successful application in specific classroom contexts.

b. Processes for reviewing PBLA guidelines and protocols should be established, to meet changing contexts, and to ensure alignment with agreed-upon standards.

c. Ongoing moderation sessions should be introduced, to support the dependability of instructor summative assessment and to ensure consistency in interpreting the CLB standards.

d. TESL education programs should incorporate the development of assessment competence (including AfL principles, and the use of the CLB framework) in all TESL programs.

5. The necessary resources must be available to sustain and develop practice. In the years ahead, external support needs to be maintained for ongoing professional learning, a PBLA community of practice, and the development of materials and resources consistent with PBLA principles to meet changing contexts.

\section{Conclusion}

The implementation of PBLA has been (a) geographically dispersed across a wide range of Canadian programs and classes, (b) systemically complex, and yet (c) rooted in best practices, as suggested by evidence-based research. At 
this point, dissemination is ongoing, and we should soon see an impact on learning, manifested in ways that reflect the wide range of learning contexts across the country. As we move forward, sustainability of the PBLA initiative will be key, but will require ongoing support for professional learning and classroom resources, development of agreed-upon standards and moderation sessions to ensure consistent application of these standards, and initiation of research to measure the impact of PBLA.

\section{Acknowledgements}

I would like to thank Joanne Pettis, PBLA Project Lead, as well as anonymous reviewers, for feedback on drafts of the article. Most importantly, I would like to acknowledge Joanne for the vision she has brought to portfolio-based language assessment in Canada. From the outset, she saw the possibilities of developing a national classroom-based assessment system based on a principled approach and grounded in research. She has nurtured the initiative from concept, through to pilot and implementation.

\section{The Author}

Tara Holmes, PhD, is a PBLA Project Lead with Joanne Pettis. She has experience as an ESL classroom instructor, program administrator, and consultant. Her research interests include classroom-based assessment and immigrant integration. She has advised on many CLB-related projects and is author of Integrating CLB Assessment into your ESL Classroom.

\section{References}

Black, P., Harrison, C., Hodgen, J., Marshall, B., \& Serret, N. (2011). Can teachers' summative assessments produce dependable results and also enhance classroom learning? Assessment in Education: Principles, Policy \& Practice, 18(4), 451-469.

Black, P., Harrison, C., Lee, C., Marshall, B., \& Wiliam, D. (2003). Assessment for learning: Putting it into practice. Berkshire, UK: Open University Press.

Black, P., \& Wiliam, D. (1998). Inside the black box: Raising standards through classroom assessment. London, UK: King's College London School of Education.

Cullingford, C. (2004). The future: Is sustainability sustainable? In J. Blewitt \& C. Cullingford (Eds.), The sustainability curriculum (pp. 245-52). London, UK: Earthscan.

Davison, C., \& Leung, C. (2009). Current issues in English language teacher-based assessment. TESOL Quarterly, 43(3), 393-415.

Gardner, J. (2010). Developing teacher assessment: an introduction. In J. Gardner, W. Harlen, L. Hayward, \& G. Stobart (Eds.), Developing teacher assessment (pp. 1-11). Berkshire, UK: Open University Press.

Gardner, J., Harlen, W., Hayward, L., Stobart, G., \& Montgomery, M. (2010). Developing teacher assessment. Berkshire, UK: McGraw Hill/Open University Press.

Harlen, W. (2004). A systematic review of the evidence of reliability and validity of assessment by teachers used for summative purposes. Research Evidence in Education Library. London, UK: EPPI-Centre, Social Science Research Unit, Institute of Education. Retrieved from http://eppi. ioe.ac.uk/cms/LinkClick.aspx?fileticket=6_1H03rsumM\%3d\&tabid=117\&mid=923

Harlen, W. (2005). Trusting teachers' judgement: research evidence of the reliability and validity of teachers' assessment used for summative purposes. Research Papers in Education, 20(3), 245-270.

Harlen, W. (2010). Professional learning to support teacher assessment. In J. Gardner, W. Harlen, L. Hayward, \& G. Stobart (Eds.), Developing teacher assessment (pp. 100-129). Berkshire, UK: Open University Press. 
Harlen, W., \& Gardner, J. (2010). Assessment to support learning. In J. Gardner, W. Harlen, L. Hayward, \& G. Stobart (Eds.), Developing teacher assessment (pp. 15-28). Berkshire, UK: Open University Press.

Harlen, W., \& Hayward, L. (2010). Embedding and sustaining developments in teacher assessment. In J. Gardner, W. Harlen, L. Hayward, G. Stobart, \& M. Montgomery (Eds.), Developing teacher assessment (pp. 155-171). Berkshire, UK: Open University Press.

Holmes, B., Gardner, J., \& Galanouli, D. (2007). Striking the right chord and sustaining successful professional development in ICT. Journal of In-Service Education, 33(4), 389-404.

Klenowski, V., \& Wyatt-Smith, C. (2014). Assessment for education: Standards, judgement and moderation. London, UK: Sage.

Leahy, S., Lyon, C., Thompson, M., \& Wiliam, D. (2005). Classroom assessment: Minute-byminute and day-by-day. Educational Leadership, 63(3), 19-24.

Leahy, S., \& Wiliam, D. (2011). From teachers to schools: Scaling up professional development for formative assessment. In J. Gardner (Ed.), Assessment and learning (2nd ed.) (pp. 49-72). London, UK: Sage.

Makosky, L. (2008). The feasibility and way forward for a standardized exit assessment and test for newcomers in LINC training. Ottawa, ON: Internal report prepared for Citizenship and Immigration Canada.

Nagy, P. \& Stewart, G. (2009). Research study on potential approaches to second language assessment. Ottawa, ON: Internal report prepared for Citizenship and Immigration Canada.

Pettis, J. (2014). Portfolio-Based Language Assessment (PBLA): Guide for teachers and programs. Ottawa $\mathrm{ON}$ : Centre for Canadian Language Benchmarks.

Ripley, D. (2012). Implementing portfolio-based language assessment in LINC programs: Benefits and challenges. TESL Canada Journal. 30(1), 69-86.

Stobart, G. (2010). Making a difference: Evaluating the impact of innovations in assessment. In J. Gardner, W. Harlen, L. Hayward, \& G. Stobart (Eds.), Developing teacher assessment. Berkshire, UK: Open University Press.

Wiliam, D. (2011). Embedded formative assessment. Bloomington, IN: Solution Tree Press. 